\title{
NANOTECHNOLOGY IN FOOD PACKAGING - A CRITICAL REVIEW
}

\author{
Sumit Goyal, Gyanendra Kumar Goyal, Researchers \\ National Dairy Research Institute, Karnal, India \\ E-mail: thesumitgoyal@gmail.com,gkg5878@yahoo.com
}

Received September 26, 2012

\begin{abstract}
Nanotechnology has an extremely high potential to benefit society through applications in food packaging. It can make the products cheaper and the production more efficient by producing less waste and using less energy. However, any new technology carries an ethical responsibility for wise application and the recognition that there are potential unforeseen risks that may come with the tremendous positive potential. The concept of nanocomposites represents a stimulating route for creating new and innovative materials, also in the area of natural polymers. The use of protective coatings and suitable packaging by the food industry has become a topic of great interest because of their potentiality for increasing the shelf life of many food products. Research and development of bio-nanocomposite materials for food applications such as packaging and other food contact surfaces is expected to grow in the next decade with the advent of new polymeric materials and composites with inorganic nanoparticles.
\end{abstract}

\section{KEY WORDS}

Nanotechnology; Food Packaging; Food Products.

The use of protective coatings and suitable packaging by the food industry has become a topic of great interest because of their potentiality for increasing the shelf life of many food products (Ahvenainen, 2003; Coles et al., 2003; Hernandez et al., 2000). By means of the correct selection of materials and packaging technologies, it is possible to keep the product quality and freshness during the time required for its commercialization and consumption (Brown, 1992; Stewart et al., 2002). A big effort to extend the shelf life and enhance food quality while reducing packaging waste has encouraged the exploration of new bio-based packaging materials, such as edible and biodegradable films from renewable resources (Tharanathan, 2003). The use of these materials, due to their biodegradable nature, could at least to some extent solve the waste problem. Nowadays, the largest part of materials used in packaging industries is produced from fossil fuels and are practically un-degradable. For this, packaging materials for foodstuff, like any other short-term storage packaging material, represent a serious global environmental problem (Kirwan \& Strawbridge, 2003). Unfortunately, so far the use of biodegradable films for food packaging has been strongly limited because of the poor barrier properties and weak mechanical properties shown by natural polymers. For this reason natural polymers were frequently blended with other synthetic polymers or, less frequently, chemically modified with the aim of extending their applications in more special or severe circumstances (Guilbert et al., 1997; Petersen et al., 1999). However, like conventional packaging, bio-based packaging must serve a number of important functions, including containment and protection of food, maintaining its sensory quality and safety, and communicating information to consumers (Robertson, 1993).

Nanotechnologies promise many stimulating changes to enhance health, wealth and quality of life, while reducing the environmental impact. The application of nanocomposites promises to expand the use of edible and biodegradable films (Lagaron et al., 2005; Sinha Ray \& Bousmina, 2005). It will help to reduce the packaging waste associated with processed foods and will support the preservation of fresh foods, extending their shelf life (Labuza \& Breene, 1988; Vermeiren et al., 1999).In addition, inorganic particles may be used to introduce multiple functionalities like colour and odours but also to act as reservoirs for the controlled release functions of drugs or fungi- 
cides (Lee et al., 2003; Li et al., 2004). Numerous food researchers are working with the aim to improve delivery of medicines or fragile micronutrients in the everyday foods by creating tiny edible capsules, or nano-particles that release their contents on demand at targeted spots in the body. It is thought to provide significant health benefits, such as reduced risk of heart attack, stroke, neurodegenerative diseases and cancer (Koo et al., 2005; Yan \& Gilbert, 2004). Although promising results were obtained, the road to successful bio-nanocomposites is still long (Sorrentio et al., 2007). This review critically discusses use of nanocomposites for bio-based packaging.

\section{BIODEGRADABLE NANOCOMPOSITES}

The extraordinary success of the nanocomposite concept in the area of synthetic polymers has stimulated new research on nanocomposites based on biodegradable polymers as matrix (Sorrentio et al., 2007). Biodegradable plastics are polymeric materials in which at least one step in the degradation process is through metabolism in the presence of naturally occurring organisms. Under appropriate conditions of moisture, temperature and oxygen availability, biodegradation leads to fragmentation or disintegration of the plastics with no toxic or environmentally harmful residue (Chandra \& Rustgi, 1998).

Biodegradable polymers can be classified according to their source:

1. Polymers directly extracted or removed from biomass (i.e. polysaccharides, proteins, polypeptides, polynucleotides).

2. Polymers produced by classical chemical synthesis using renewable bio-based monomers or mixed sources of biomass and petroleum (i.e. polylactic acid or bio-polyester)

3. Polymers produced by micro-organism or genetically modified bacteria (polyhydroxybutyrate, bacterial cellulose, xanthan, curdian, pullan).

Description of biopolymers is available in literature (Doi \& Steinbuechel, 2002; Kaplan, 1998; Mohanty et al., 2005; Steinbuchel, 2003; Sorrentio et al., 2007). The problems associated with biodegradable polymers are threefold: performance, processing, and cost. Although these factors are somewhat interrelated, problems due to "performance and processing" are common to all biodegradable polymers in spite of their origin (Scott, 2000; Trznadel, 1995). In particular, brit- tleness, low heat distortion temperature, high gas and vapour permeability, poor resistance to protracted processing operations have strongly limited their applications. The application of nanotechnology to these polymers may open new possibilities for improving not only the properties but also the same time the cost-price-efficiency.

Owing to the nanometer-size particles obtained by dispersion, these nanocomposites can exhibit markedly improved mechanical, thermal, barrier and physico-chemical properties, when compared with the starting polymers and conventional (microscale) composites. In particular, they show great promise in providing excellent barrier properties, due to the presence of the clay layers able to delay the molecule pathway making the diffusive path more tortuous (Bharadwaj, 2001; Neilsen, 1967).

Recently, several research groups started the preparation and characterization of various kinds of biodegradable polymer nanocomposites showing properties suitable for a wide range of applications (Sinha Ray \& Bousmina, 2005). So far, the most studied biodegradable nanocomposites suitable for packaging applications are starch and derivates, polylactic acid (PLA), poly(butylene succinate) (PBS), polyhydroxybutyrate (PHB), and aliphatic polyester as PCL.

\section{(i) Starch and their derivates:}

Starch is a promising raw material because of its cyclic availability from many plants and excessive production with regard to current needs and its low cost (Gonera \& Cornillon, 2002; Smits et al., 1998). It is known to be completely degradable in soil and water and can promote the biodegradability of a non-biodegradable plastic when blended. As a packaging material, starch alone does not form films with appropriate mechanical properties unless it is first plasticized, or chemically modified. Common plasticizers for hydrophilic polymers, such as starch, are glycerol and other low molecular weight polyhydroxy compounds, polyethers, urea and water. When starch is treated in an extruder by application of both thermal and mechanical energy, it is converted to a thermoplastic material. In the production of thermoplastic starches, plasticizers are expected to efficiently reduce intra-molecular hydrogen bonds and to provide stability to product properties. There are many opportunities for using starch as packaging material (Kim \& Pometto, 1994). Due to its hygroscopic nature, starch-based absorbent pads are expected to pro- 
vide a potential alternative to conventional absorbent for meat exudation (Smith et al., 1995). Films or bag, starch could be employed as packaging for fruits and vegetables, snacks or dry products. In these applications, however, efficient mechanical, oxygen and moisture protection is needed. Thermoplastic starch (TPS) alone often cannot meet all these requirements. In particular, because of the hydrophilicity of the starch the performance changes during and after processing, due to the water content changes. To overcome this drawback, many different routes have been reported.

Clay, as potential filler, has been chosen for improving the properties of TPS in such applications (Chen \& Evans, 2005; De Carvalho et al., 2001; McGlashan \& Halley, 2003; Wilhelm, Sierakowski et al., 2003; Yoon \& Deng, 2006). It has been shown that both the tensile strength and the elongation at break of TPS were increased with the presence of small amounts (less than $5 \%$ ) of sodium montmorillonite (Park et al., 2002). In addition, the decomposition temperature was increased while the relative water vapour diffusion coefficient of TPS was decreased (Park et al., 2003).

Starch/clay nanocomposite films were obtained by dispersing montmorillonite nanoparticles via polymer melt processing techniques. Mechanical characterization results show an increase of modulus and tensile strength. In addition, the conformity of the resulting material samples with actual regulations and European directives on biodegradable materials was verified by migration tests (Avella et al., 2005).

(ii) Polylactic acid (PLA):

The use of conventional chemical synthesis for the production of polymers gives a wide spectrum of possible biopolyesters. To date, PLA is the polymer with the highest potential for a commercial major scale production of renewable packaging materials. Lactic acid, the monomer of PLA, may easily be produced by fermentation of carbohydrate feedstock. The carbohydrate feedstock may be agricultural products such as maize, wheat, molasses, and whey. The properties of the PLA material are highly related to the ratio between the two forms ( $\mathrm{L}$ or $\mathrm{D}$ ) of the lactic acid monomer. L-PLA is a material with a very high melting point and high crystallinity, whereas a mixture of D- and L-PLA results in an amorphous polymer with a low glass transition temperature.

\section{(iii) Polyhydroxybutyrate (PHB):}

PHB is accumulated by a large number of bacteria as energy and carbon reserves. Due to its biodegradability and biocompatibility this biopolyester may easily find industrial applications (Van der Walle et al., 2000). PHB is a typical highly crystalline thermoplastic with a very low water vapour permeability which is close to that of low density polyethylene (LDPE). The major drawback for the commercial use of the PHB homopolymer is represented by an unfavorable ageing process.

Potentially, PLA and PHB offer numerous opportunities in packaging applications. They can be formed into films or used to make moulded objects. In addition, they are compatible with many foods, such as dairy products, beverage, fresh meat products and ready meals. So far, the large-scale use of biodegradable polyesters (PHB, PLA) as packaging material is hampered by their high cost as well as their low performances. Also, in this case, the use of nanometric filler promises to expand its application. Many papers (Chang et al., 2003; Chen et al., 2004; Choi et al., 1997; Liu et al., 2002; Maiti et al., 2003; Ogata et al., 1997; Park et al., 2001; Paul et al., 2003; Pluta et al., 2002; Sinha Ray et al., 2002; Sinha Ray et al., 2003; Sorrentio et al., 2007) report the use of PHB and PLA for the preparation of polymer/clay nanocomposite materials. Bandyopadhyay et al. (1999) reported the preparation of PLA-clay nanocomposites with much improved mechanical and thermal properties. Instead, the formation of nanocomposite materials from PHB seems to be difficult, and rather moderate improvements in properties have been reported in the case of PHB as matrix material (Maiti et al., 2003). Solvent casting of mixtures of PLA and organophilic clay in chloroform resulted in materials with an enhanced crystallization tendency and increased Young's modulus (Ogata et al., 1997). However, the glass transition temperature increases only slightly with increasing clay content. This may be due to the microcomposite structure rather than nanocomposite structure. As a matter of fact, a strong tendency of tactoids formation was observed. The PLA/layered silicate nanocomposites, prepared by simple melt extrusion, exhibited remarkable improvement of material properties in both solid and melt states compared to the matrix without clay (Sinha Ray et al., 2002). Nanocomposites of the PLA and PLA/PCL blends were obtained by 
melt-mixing with a properly modified kaolinite (Cabedo et al., 2006). Also, in this case, all nanocomposites showed an improvement in the gas barrier, mechanical and thermal properties with regard to the polymers and blends without clay.

\section{(iv) Polycaprolactone (PLC):}

PCL is linear polyester manufactured by ring-opening polymerization of 3-caprolactone. It is a semicrystalline polymer with a high degree of crystallinity (around 50\%). PCL exhibits high elongation at break and low modulus. Its physical properties and commercial availability make it very attractive as a material for commodity applications. PCL is also interesting for applications in the medical and agricultural areas (Nakayama et al., 1997). Due to its low melting point, in conventional applications it must be blended with other polymers (Ishiaku et al., 2002; Lee et al., 2002; Lim et al., 2002; Kesel et al., 1997). Many research groups worked on the preparation of PCL/organically modified layered silicate (OMLS) nanocomposites with better physical properties (Gorrasi et al., 2002; Gorrasi et al., 2004; Messersmith \& Giannelis, 1993; Messersmith \& Giannelis, 1995; Kojima et al., 1993; Utracki et al., 2003; Tortora et al., 2002; Usuki et al., 1993; Bharadwaj et al., 2002). Di Iannace et al. (2003) reported the preparation of melt PCL/OMLS nanocomposites using two different types of OMLS. The thermal and rheological behaviour of the prepared nanocomposites was investigated and analyzed in terms of processing conditions and types of OMLS.

\section{NANOCOMPOSITE-BASED EDIBLE MATERIAL}

Edible films and coatings are defined as thin, continuous layers of edible material used as a coating or as a film placed between food components to provide a barrier to mass transfer (Balasubramaniam et al., 1997; Guilbert et al., 1997). They essentially differ in the mode of formation and application to foods. Edible coatings are applied and formed directly on the food product either by addition of a liquid filmforming solution or by molten compounds. They may be applied with a paintbrush, by spraying, dipping or fluidizing. In other words, edible coatings form an integral part of the food product and hence should not impact the sensory characteristics of the food (Baldwin et al., 1996; Banks, 1985; Bender et al., 1993). Edible films, in contrast, are freestanding structures, formed and then applied to foods. They are formed by casting or by traditional plastic processing techniques, such as extrusion (Baldwin, 1994; Park et al., 1996).

Components of edible films and coatings can be divided into two categories: water-soluble polysaccharides (hydrocolloids) and lipids. Suitable polysaccharides include cellulose derivatives, alginates, pectins, starches, chitosan and other polysaccharides (El Ghaouth et al., 1991). However, great differences exist in how easily these substances can form films of good integrity (Park et al., 1994). The information with regard to diverse capabilities and the huge chemistry, technology and applications of the water-soluble polysaccharides often referred to as gums or hydrocolloids is available (Aspinall, 1970; Glicksman, 1984; Wurzburg, 1986). Hydrocolloids serve numerous diverse roles such as providing hardness, crispness, compactness, thickening quality, viscosity, adhesiveness, gel-forming ability and mouth-feel (Whistler \& Daniel, 1990). Many lipid compounds such as animal and vegetable fats have been used to make edible films and coatings. Suitable lipids include waxes, acylglycerols, and fatty acids. Lipid films have excellent moisture barrier properties or as coating agents for adding gloss to confectionery products. Waxes are commonly used for coating fruits and vegetables to retard respiration and lessen moisture loss (Avena-Bustillos et al., 1994). Acetylated monoglycerides are frequently added to wax formulations to add pliability to the coating (Avena- Bustillos et al., 1997). Coatings to sucrose fatty acid esters are effective moisture barriers for maintaining the crispness of snack foods (Kester \& Fennema, 1989) and for extending the shelf life of apples (Drake et al., 1987). Many lipids exist in a crystalline form and their individual crystals are highly impervious to gases and water vapour (Greener \& Fennema, 1989b; Kamper \& Fennema, 1984). Since the permeate can pass between crystals, the barrier properties of crystalline lipids are highly dependent on the intercrystalline packing arrangement. Although fatty acids and fatty alcohols are effective barriers to water vapour, their fragility requires their use in conjunction with a supporting matrix. Sometimes, composite films can be formulated to combine the advantages of the lipid and hydrocolloid components and lessen the disadvantages of each (Greener \& Fennema, 1989a; Kamper \& Fennema, 1984). 
Even if edible films have been extensively studied and applied, up to now only few research works indicate the possibility of incorporation nano-particles in order to improve the physical properties of these materials. The research of Mangiacapra et al. (2005) demonstrated the possibility to lower the diffusion of oxygen by adding clay montmorillonite into pectins. Similarly, Zheng et al. (2002) reported a considerable improvement of the physical properties in nanocomposites prepared by gelatine and montmorillonite. An appreciable increase in stability of chitosan/layered nanocomposites was also reported (Darder et al., 2003). Despite the lack of specific literature data, there is sufficient evidence to establish the beneficial effects of inorganic nanofiller on these materials, among which there are improved retention of flavour, acids, sugars, texture and colour, increased stability during shipping and storage, improved appearance and reduced spoilage. Additionally, edible coatings and films are a viable means for incorporating food additives and other substances to enhance product colour, flavour, and texture and to control microbial growth (Siragusa \& Dickson, 1992).

Nano-particles can be used as carrier of antimicrobials and additive. Studies have demonstrated their ability to stabilize the additives and efficiently control their diffusion into the food as well as between different regions, i.e., surface vs. bulk of a food system. This control can be especially important for long-term storage of foods or for imparting specific desirable characteristics, such as flavour to a food system.

\section{PROPERTIES \& APPLICATIONS OF NANOCOMPOSITES}

Nanocomposites are mixtures of polymers with inorganic or organic additives having certain geometries like fibres, flakes, spheres or particulates. The use of nanoscale fillers is leading to the development of polymer nanocomposites and represents a radical alternative to these conventional polymer composites (Alexandre \& Dubois, 2000; Giannelis, 1996; Sinha Ray \& Okamoto, 2003). This new generation of composites exhibits significant improvements in modulus, dimensional stability and solvent or gas resistance with respect to the pristine polymer. Nanocomposites also offer extra benefits like low density, transparency, good flow, better surface properties and recyclability. It is worth noting that these improvements are obtained at very low filler contents (generally lower than 5\%). The enhancement of many properties resides in the fundamental length scales dominating the morphology and properties of these materials. The inorganic particles have at least one dimension in the nanometer (from 1 to $100 \mathrm{~nm}$ ) range. Various inorganic nano-particles have been recognized as possible additives to enhance the polymer performance. Some examples of these particles are represented by the solid layered, the synthetic polymer nanofibres, the cellulose nano-whiskers and the carbon nanotube. Among these, up to now only the layered inorganic solids like clay have attracted some attention by the packaging industry. This is not only due to their availability and low cost but also due to their significant enhancements and relative simple processability.

The first successful example of a polymerclay hybrid, developed at Toyota Central Research Laboratories in 1986 was a nylon-clay hybrid (Kawasumi, 2004). The characteristic feature of clay minerals is the stacked arrangement of negatively charged silicate layers with a thickness of about $1 \mathrm{~nm}$ and lateral extensions of about $100 \mu \mathrm{m}$.

Layered double hydroxides (LDHs) represent another interesting class of capable nano-fillers for polymers (Fischer et al., 1999; Wei et al., 2004). LDH particles are constituted by magnesium-aluminium hydroxide layers. In contrast to layered silicates the hydroxide layers display a positive surface charge which is counterbalanced by anions located in the domains between adjacent layers (De Roy, 1998).

Two major steps are involved in solid layered dispersion in polymers: intercalation and exfoliation. In the intercalation step, the spacing between individual layers, called d-spacing, increases from its intrinsic value as polymer chains or monomer molecules diffuse into the clay galleries. In an intercalated state, the inorganic layers remain parallel to each other; in exfoliation, the individual clay particles are separated from the intercalated tactoids and are dispersed in the matrix polymer with no apparent interparticle interactions. Whether a mixture of polymer and organic modified nano-particles produces an exfoliated or intercalated nanocomposite critically depends on the characteristics of the polymer matrix and the organic modifiers. These characteristics include the nature of the polymer as well as the type, packing density, and the size of the 
organic modifiers on the inorganic surface (Alexandre \& Dubois, 2000; Pantoustier et al., 2001). The organic component of the organo-clay or modified hydrotalcite increases significantly the compatibility between the polymer and the filler. The surface of the silicate or hydrotalcite layers, therefore, becomes accessible to the polymer chains and intercalation or full delamination (exfoliation) of the filler particles can occur during the mixing of the filler with the polymer. Generally, intercalation of polymer chains into the inorganic galleries is done by using one of the following two approaches: insertion of suitable monomers in the galleries and subsequent polymerization or direct insertion of polymer chains into the galleries from either solution or the melt.

In the first approach, also identified as "insitu polymerization", the nano-filler is swollen within the liquid monomer so as the polymer formation can occur between the intercalated sheets. Polymerization can be initiated by heat or radiation, by the diffusion of a suitable initiator, or by an organic initiator or catalyst fixed through cationic exchange inside the interlayer before the swelling step by the monomer (Sinha Ray \& Okamoto, 2003; Lepoittevin et al., 2002).

In the second approach, the layered inorganic is mixed with the polymer matrix in either the molten state or a solvent in which the polymer is soluble. Under these conditions, and if the layer surfaces are sufficiently compatible with the chosen polymer, the polymer can crawl into the interlayer space and form either an intercalated or an exfoliated nanocomposite. An alternative route is represented by the template method, widely used for the synthesis of double-layer hydroxide-based nanocomposites (De Roy, 1998; Oriakhi et al., 1997; Wilson et al., 1999). However, it is less developed for layered silicates.

In the case of the natural polymers the choice of the suitable method for the preparation of nanocomposites is limited by the processing possibilities of the natural materials. Since nature itself produces the possible matrix polymers, only blending/compounding with suitable inorganic particles, either in the melt or in solution is an accessible manufacturing possibility. Recently, a new alternative method for the preparation of nanocomposites, which involves a solid-state mixing at room temperature (ball milling) (Mangiacapra et al., 2005) was proposed. In this case, solid layered dispersion was promoted by the energy transfer between milling tools (generally balls) and polymer/inorganic particles mixture, which in turn results grinded and intimately mixed. Among the available techniques used for nanocomposites preparation, ball milling has the considerable advantage of not requiring the use of high temperature or solvent treatments.

\section{LEGAL AND ETHICAL BARRIERS}

Nanotechnology has an extremely high potential to benefit society through applications in food packaging. It can make the products cheaper and the production more efficient by producing less waste and using less energy. However, any new technology carries an ethical responsibility for wise application and the recognition that there are potential unforeseen risks that may come with the tremendous positive potential. In parallel to the technical evolution of nanotechnologies, it is expected that there will be new regulatory directives and guidelines to accommodate nanotechnology based products (Sorrentio et al., 2007). At present no government has developed any regulatory regime, specifically referring to the production and application of nano-particles. Also in the frame of chemical legislation, particle size does not play a role for the registration of new substances. A lot of new knowledge has to be generated on how nano-material based processes and products may interfere with human health before any regulation in this field can be established (Borm et al., 2006; Derfus et al., 2004; Hoet et al., 2004; Oberdorster, 2004). In addition, limited eco-toxicological data for nano-materials precludes a systematic assessment of the impact of nano-particles on ecosystems (Colvin, 2003). The ability to assess the toxicity of intentionally produced nano-materials by extrapolating from the current particle toxicological database was examined by several reports (Dreher, 2004; European NanoSafe, 2004). Their findings indicated a high degree of uncertainty in the prediction of the toxicity of such nanomaterials.

Despite this lack in knowledge, a handful of food and nutrition products containing invisible and un-labeled nanoscale additives are already on supermarket shelves (Mazzola, 2003; Gaskell et al., 2004). With respect to nano-fillers discussed in this review, it is important to point out that the majority of the works present in literature make use of additives and surfactants in order to increase the compatibility between the polymer and the filler. Except for specific product developed 
by few companies around the world, these additives are not food contact approved as yet (Sorrentio et al., 2007).

Lagaron et al. (2005) stated: at the moment "there is no reason to believe that material nanocomposites making use of substances in positive lists can impose any immediate risk threat for food contact applications". The actual knowledge does not suggest any justification for imposing a ban on the production of nano-clays or LDHs based nanocomposites for food packaging applications (Cole \& Bergeson, 2006). However, a better knowledge of the effects of these nanoparticles on the human health and environment is necessary for an adequate regulation of their use for food contact applications.

\section{CONCLUSION}

The concept of nanocomposites represents a stimulating route for creating new and innovative materials, also in the area of natural polymers. Materials with a large variety of properties have been realized, and even more remain to be explored. The nanocomposite materials obtained by mixing natural polymers and sheets of crystalline solid layered clays or LDHs offer a great variety of property profiles. They are even able to compete both in price and in performance, with synthetic polymeric materials in packaging.

In spite of the great possibilities existing for packaging in bio-based nanocomposite materials, the future scenario is difficult to predict. It is hoped that simple traditional packaging will be replaced with multi-functional intelligent packaging. The next generation of packaging materials will be able to fit the requirements of preserving fruit, vegetable, beverage, wine, dairy products and other food products. By adding appropriate nano-particles, it will be possible to produce packages with stronger mechanical, barrier and thermal performance. Nano-structured materials will prevent the invasion of bacteria and microorganisms as a concern for food safety. The nano-sensors embedded in the packaging may alert the consumer if a food has deteriorated.

\section{REFERENCES}

Ahvenainen R. (2003). Novel Food Packaging Techniques. Woodhead Publishing Company. CRC Press. London.

Alexandre, M., \& Dubois, P. (2000). Polymerlayered silicate nanocomposites preparation, properties and uses of a new class of materials. Material Science and Engineering, 28: $1-11$.

Avella, M., De Vlieger, J. J., Errico, M. E., Fischer, S., Vacca, P., \& Volpe, M. G. (2005). Biodegradable starch/clay nanocomposite films for food packaging applications. Food Chemistry, 93: 467-474.

Avena-Bustillos, R. J., Krochta, J. M., \& Saltveit, M. E. (1997). Water vapour resistance of red delicious apples and celery sticks coated with edible caseinate-acetylated monoglyceride films. Journal of Food Science, 62(2): 51-354.

Avena-Bustillos, R. J., Krochta, J. M., Saltveit, M. E., Rojas Villegas, R. J., \& SaucedaPbrez, J. A. (1994). Optimization of edible coating formulations on zucchini to reduce water loss. Journal of Food Engineering, 21: 197-214.

Balasubramaniam, V. M., Chinnan, M. S., Mallikarjunan, P., \& Philips, R. D. (1997). The effect of edible film on oil uptake and mois- ture retention of deep-fat fried poultry product. Journal of Food Process Engineering, 20(1), 17-29.

Baldwin, E. (1994). Edible coatings for fresh fruits and vegetables: past, present and future. In J. M. Krochta, E. A. Baldwin, \& M. Nisperos-Carriedo (Eds.), Edible coatings and films to improve food quality (pp. 2564). Basel: Technomic.

Baldwin, E. A., Nisperos, M. O., Chen, X., \& Hagenmaier, R. D. (1996). Improving storage life of cut apples and potato with edible coating. Postharvest Biology and Technology, 9(2): 151-163.

Bandyopadhyay, S., Chen, R., \& Giannelis, E. P. (1999). Biodegradable organiceinorganic hybrids based on poly (L lactide). Polymeric Materials Science and Engineering, 81: 159160.

Banks, N. H. (1985). Responses of banana fruit to prolong coating at different times relative to the initiation of ripening. Scientia Horticulturae, 26: 149-157.

Bender, R. J., Brecht, J. K., Sargent, S. A., Navarro, J. C., \& Campbell, C. A. (1993). Ripening initiation and storage performance of avocados treated with an edible-film coating. Acta Horticulturae, 343: 184-186. 
Bharadwaj, R. K. (2001). Modeling the barrier properties of polymer-layered silicate nanocomposites. Macromolecules, 34: 91899192.

Bharadwaj, R. K., Mehrabi, A. R., Hamilton, C., Murga, M. F., Chavira, A., \& Thompson, A. K. (2002). Structure-property relationships in cross-linked polyestereclay nanocomposites. Polymer, 43: 3699-3705.

Borm, P. J. A., Robbins, D., Haubold, S., Kuhlbusch, T., Fissan, H., Donaldson, K., et al. (2006). The potential risks of nanomaterials: a review carried out for ECETOC. Particle and Fibre Toxicology, 3: 11.

Brown, W. E. (1992). Plastics in food packaging: Properties, design, and fabrication. New York, NY: Marcel Dekker.

Cabedo, L., Feijoo, J. L., Villanueva, M. P., Lagaron, J. M., \& Gimenez, E. (2006). Optimization of biodegradable nanocomposites based on a PLA/PCL blends for food packaging applications. Macromolecular Symposia, 233: 191-197.

Chandra, R., \& Rustgi, R. (1998). Biodegradable polymers. Progress in Polymer Science, 23, 1273-1335.

Chang, J.-H., Uk-An, Y., \& Sur, G. S. (2003). Poly (lactic acid) nanocomposites with various organoclays. I. Thermomechanical properties, morphology, and gas permeability. Journal of Polymer Science, Part B: Polymer Physics, 41: 94-103.

Chen, B., \& Evans, J. R. G. (2005). Thermoplastic starcheclay nanocomposites and their characteristics. Carbohydrate Polymers, 61(4): 455-463.

Chen, G. X., Hao, G. J., Guo, T. Y., Song, M. D., \& Zhang, B. H. (2004). Crystallization kinetics of poly (3-hydroxybutyrate-co-3- hydroxyvalerate)/clay nanocomposites. Journal of Applied Polymer Science, 93: 655661.

Choi, H. J., Kim, J. H., \& Kim, J. (1997). Mechanical spectroscopy studies on biodegradable synthetic and biosynthetic aliphatic polyesters. Macromolecular Symposia, 119: 149-155.

Cole, M. F., \& Bergeson, L. (2006). Regulatory report FDA, Regulation of Food Packaging Produced Using Nano technology. Food Safety Magazine. http://www.foodsafetymagazine.com/issues/ 0604/ col03.htm

Coles, R., McDowell, D., \& Kirwan, M. J. (2003). Food packaging technology. Oxford, UK: Blackwell Publishing Ltd.

Colvin, V. L. (2003). The potential environmen- tal impact of engineered nanomaterials. Nature Biotechnology, (10): 1166-1170.

Darder, M., Colilla, M., \& Ruiz-Hitzky, E. (2003). Biopolymere clay nanocomposites based on chitosan intercalated in montmorillonite. Chemistry of Materials, 15: 37743780.

De Carvalho, A. J. F., Curvelo, A. A. S., \& Agnelli, J. A. M. (2001). A first insight on composites of thermoplastic starch and kaolin. Carbohydrate Polymers, 45, 189-194.

De Roy, A. (1998). Lamellar double hydroxides. Molecular Crystals and Liquid Crystals, 311: 173-193.

Derfus, A. M., Chan, W. C. W., \& Bhatia, S. N. (2004). Probing the cytotoxicity of semiconductor quantum dots. Nano Letters, 4 (1): 11-18.

Di, Y., Iannace, S., Di Maio, E. D., \& Nicolais, L. (2003). Nanocomposites by melt intercalation based on polycaprolactone and organoclay. Journal of Polymer Science, Part B: Polymer Physics, 41: 670-678.

Doi, Y., \& Steinbuechel, A. (2002). Polyesters. III, Applications and commercial products. In Biopolymers, 4. Weinheim, Germany: Wiley-VCH Verlag GmbH.

Drake, S. R., Fellman, J. K., \& Nelson, J. W. (1987). Post harvest use of sucrose polymers for extending the shelf-life of stored Golden Delicious apples. Journal of Food Science, 52, 1283-1285.

Dreher, K. L. (2004). Health and environmental impact of nanotechnology: toxicological assessment of manufactured nanoparticles. Toxicological Sciences, 77: 3-5.

El Ghaouth, A. E., Arul, J., Ponnampalam, R., \& Boulet, M. (1991). Use of chitosan coating to reduce water loss and maintain quality of cucumber and bell pepper fruits. Journal of Food Processing and Preservation, 15: 359368.

European NanoSafe Report (2004). Technical analysis: industrial application of nanomaterials chances and risks. www.nano.uts. edu.au/nanohouse/nanomaterials\%20risks.p df

Fischer, H. R., Gielgens, L. H., \& Koster, T. P. M. (1999). Nanocomposites from polymers and layered minerals. Acta Polymerica, 50: 122-126.

Gaskell, G., Eyck, T. T., Jackson, J., \& Veltri, G. (2004). From our readers: Public attitudes to nanotech in Europe and the United States. Nature Materials, 3: 496.

Giannelis, E. P. (1996). Polymer layered silicate nanocomposites. Advanced Materials, 8 (1): 
29-35.

Gonera, A., \& Cornillon, P. (2002). Gelatinization of starch/gum/sugar system studied by using DSC, NMR and CSLM. Starch, 54: 508-516.

Gorrasi, G., Tortora, M., Vittoria, V., Galli, G., \& Chiellini, E. (2002). Transport and mechanical properties of blends of poly (3caprolactone) and a modified montmorillonite-poly (3-caprolactone) nanocomposite. Journal of Polymer Science, Part B: Polymer Physics, 40: 1118-1124.

Gorrasi, G., Tortora, M., Vittoria, V., Pollet, E., Alexandre, M., \& Dubois, P. (2004). Physical properties of poly (3-caprolactone) layered silicate nanocomposites prepared by controlled grafting polymerization. Journal of Polymer Science, Part B: Polymer Physics, 42: 1466-1475.

Greener, I. K., \& Fennema, O. R. (1989a). Barrier properties and surface characteristics of edible, bilayer films. Journal of Food Science, 54 (6): 1393-1399.

Greener, I. K., \& Fennema, O. R. (1989b). Evaluation of edible bilayer films for use as moisture barrier for food. Journal of Food Science, 54 (6): 1400-1406.

Guilbert, S., Cuq, B., \& Gontard, N. (1997). Recent innovations in edible and/or biodegradable packaging materials. Food Additives and Contaminants, 14 (6): 741-751.

Hernandez, R., Selke, S. E. M., \& Cultler, J. (2000). Plastics packaging: properties, processing, applications, regulations. $\mathrm{Mu}-$ nich, Germany: Hanser Gardner Publications.

Hoet, H. M. P., Nemmar, A., \& Nemery, B. (2004). Health impact of nanomaterials? Nature Biotechnology, 22(1): 19.

Ishiaku, U. S., Pang, K. W., Lee, W. S., \& Ishak, Z. A. M. (2002). Mechanical properties and enzymic degradation of thermoplastic and granular sago starch filled poly (3caprolactone). European Polymer Journal, 38: 393-401.

Kamper, S. L., \& Fennema, O. R. (1984). Water vapor permeability of an edible fatty acid, bilayer film. Journal of Food Science, 49: 1482-1485.

Kaplan, D. L. (1998). Biopolymers from renewable resources. Berlin, Germany: Springer.

Kawasumi, M. (2004). The discovery of polymereclay hybrids. Journal of Polymer Science, Part A: Polymer Chemistry, 42: 819-824.

Kesel, C. D., Wauven, C. V., \& David, C. (1997). Biodegradation of polycaprolactone and its blends with poly(vinylalcohol) by micro-organisms from a compost of household refuse. Polymer Degradation and Stability, 55: 107-113.

Kester, J. J., \& Fennema, O. R. (1989). An edible film of lipids and cellulose ethers: barrier properties to moisture vapor transmission and structural evaluation. Journal of Food Science, 54 (6): 1383-1389.

Kim, M., \& Pometto III, O. R. (1994). Food packaging potential of some novel degradable starchepolyethylene plastics. Journal of Food Protection, 57: 1007-1012.

Kirwan, M. J., \& Strawbridge, J. W. (2003). Plastics in food packaging. Food Packaging Technology, 174-240.

Kojima, Y., Usuki, A., Kawasumi, M., Okada, A., Karauchi, T., \& Kamigaito, O. (1993). One-pot synthesis of nylon-6-clay hybrid. Journal of Polymer Science, Part A: Polymer Chemistry, 31: 1755-1758.

Koo, O. M., Rubinstein, I., \& Onyuksel, H. (2005). Role of nanotechnology in targeted drug delivery and imaging: a concise review. Nanomedicine: Nanotechnology, Biology and Medicine, 1: 193-212.

Labuza, T. P., \& Breene,W. M. (1988). Application of active packaging for improvement of shelf-life and nutritional quality of fresh and extended shelf-life foods. Journal of Food Processing and Preservation, 13: 1-69.

Lagaron, J. M., Cabedo, L., Cava, D., Feijoo, J. L., Gavara, R., \& Gimenez, E. (2005). Improving packaged food quality and safety. Part 2: nanocomposites. Food Additives and Contaminants, 22 (10): 994-998.

Lee, C. H., An, D. S., Park, H. J., \& Lee, D. S. (2003). Widespectrum antimicrobial packaging materials incorporating nisin and chitosan in the coating. Packaging Technology and Science, 16: 99-106.

Lee, S. R., Park, H. M., Lim, H. L., Kang, T., Li, X., Cho, W. J. (2002). Microstructure, tensile properties, and biodegradability of aliphatic polyester/clay nanocomposites. Polymer, 43: 2495-2500.

Lepoittevin, B., Pantoustier, N., Alexander, M., Calberg, C., Jerome, R., \& Dubois, P. (2002). Polyester layered silicate nanohybrids by controlled grafting polymerization. Journal of Materials Chemistry, 12: 35283532.

Lim, S. T., Hyun, Y. H., Choi, H. J., \& Jhon, M. S. (2002). Synthetic biodegradable aliphatic polyester/montmorillonite nanocomposites. Chemistry of Materials, 14: 1839-1844.

Liu, W., Yang, H., Wang, Z., Dong, L., \& Liu, J. (2002). Effect of nucleating agents on the 
crystallization of poly(3-hydroxybutyratecohydroxy valerate). Journal of Applied Polymer Science, 86: 2145-2152.

Maiti, P., Batt, C. A., \& Giannelis, E. P. (2003). Renewable plastics: synthesis and properties of PHB nanocomposites. Polymer Materials Science Engineering, 88, 58-59.

Mangiacapra, P., Gorrasi, G., Sorrentino, A., \& Vittoria, V. (2005). Biodegradable nanocomposites obtained by ball milling of pectin and montmorillonites. Carbohydrate Polymers, 64 (4): 516-523.

Mazzola, L. (2003). Commercializing nanotechnology. Nature Biotechnology, 21 (10): 1137-1143.

McGlashan, S. A., \& Halley, P. J. (2003). Preparation and characterization of biodegradable starch-based nanocomposite materials. Polymer International, 52: 1767-1773.

Messersmith, P. B., \& Giannelis, E. P. (1993). Polymer-layered silicate nanocomposites: in situ intercalative polymerization of ecaprolactone in layered silicates. Chemistry of Materials, 5: 1064-1066.

Messersmith, P. B., \& Giannelis, E. P. (1995). Synthesis and barrier properties of poly(3caprolactone)-layered silicate nanocomposites. Journal of Polymer Science, Part A: Polymer Chemistry, 33: 1047-1057.

Mohanty, A. K., Misra, M., \& Drzal, L. T. (2005). Natural fibers, biopolymers, and biocomposites. Boca Raton, FL: CRC Press LLC.

Nakayama, A., Kawasaki, N., Maeda, Y., Arvanitoyannis, I., Ariba, S., \& Yamamoto, N. (1997). Study of biodegradability of poly (3- valerolactone-co-L-lactide). Journal of Applied Polymer Science, 66: 741-748.

Neilsen, L. E. (1967). Models for the permeability of filled polymers. Journal of Macromolecular Science (Chemistry), A1 (5): 929942.

Oberdorster, E. (2004). Manufactured nanomaterials (fullerenes, C60) induce oxidative stress in the brain of juvenile largemouth bass. Environmental Health Perspectives, 112 (10): 1058-1062.

Ogata, N., Jimenez, G., Kawai, H., \& Ogihara, T. (1997). Structure and thermal/mechanical properties of poly (L-lactide)-clay blend. Journal of Polymer Science, Part B: Polymer Physics, 35: 389-396.

Oriakhi, C. O., Farr, I. V., \& Lerner, M. M. (1997). Thermal characterization of poly(styrene sulfonate)/layered double hydroxide nanocomposites. Clays and Clay Minerals, 45: 194202.
Pantoustier, N., Alexandre, M., Degee, P., Calberg, C., Jerome, R., Henrist, C., et al. (2001). Poly (3-caprolactone) layered silicate nanocomposites: effect of clay surface modifiers on the melt intercalation process. e-Polymer, 9: 1-9.

Park, H. J., Chinnan, M. S., \& Shewfelt, R. L. (1994). Edible corn-zein film coatings to extend storage life of tomatoes. Journal of Food Processing and Preservation, 18: 317331.

Park, H.-M., Li, X., Jin, C.-Z., Park, C.-Y., Cho, W.-J., \& Ha, C.-S. (2002). Preparation and properties of biodegradable thermoplastic starch/clay hybrids. Macromolecular Materials and Engineering, 287 (8):553-558.

Park, H. W., Lee, W. K., Park, C. Y., Cho, W. J., \& Ha, C. S. (2003). Environmentally friendly polymer hybrids: Part I. Mechanical, thermal, and barrier properties of thermoplastic starch/clay nanocomposites. Journal of Materials Science, 38: 909-915.

Park, J. W., Testin, R. F., Vergano, P. J., Park, H. J., \& Weller, C. L. (1996). Application of laminated edible films to potato chip packaging. Journal of Food Science, 61 (4): 766$768,777$.

Park, S. H., Choi, H. J., Lim, S. T., Shin, T. K., \& Jhon, M. S. (2001). Viscoelasticity of biodegradable polymer blends of poly(3- hydroxybutyrate) and poly(ethylene oxide). Polymer, 42: 5737-5742.

Paul, M.-A., Alexandre, M., Degee, P., Henrist, C., Rulmont, A., \& Dubois, P. (2003). New nanocomposite materials based on plasticized poly(L-lactide) and organo-modified montmorillonites: thermal and morphological study. Polymer, 44: 443-450.

Petersen, K., Nielsen, P. V., Bertelsen, G., Lawther, M., Olsen, M. B. Nilssonk, N. H., et al. (1999). Potential of biobased materials for food packaging. Trends in Food Science \& Technology, 10: 52-68.

Pluta, M., Galeski, A., Alexandre, M., Paul, M.A., \& Dubois, $\quad$ P. (2002).Polylactide/montmorillonite nanocomposites and microcomposites prepared by melt blending: structure and some physical properties. Journal of Applied Polymer Science, 86 (6): 1497-1506.

Robertson, G. L. (Ed.). (1993). Food packaging: Principles and practice. New York, NY: Marcel Dekker.

Scott, G. (2000). Green polymers. Polymer Degradation and Stability, 68: 1-7.

Sinha Ray, S., \& Bousmina, M. (2005). Biodegradable polymers and their layered silicate 
nanocomposites: in greening the 21st century materials world. Progress in Material Science, 50: 962-1079.

Sinha Ray, S., Maiti, P., Okamoto, M., Yamada, K., \& Ueda, K. (2002). New polylactide/layered silicate nanocomposites. 1. Preparation, characterization and properties. Macromolecules, 35: 3104-3110.

Sinha Ray, S., \& Okamoto, M. (2003). Polymer/layered silicate nanocomposites: a review from preparation to processing. Progress in Polymer Science, 28: 15391641.

Sinha Ray, S., Okamoto, K., Maiti, P., \& Okamoto, M. (2002). New poly(butylene succinate)/layered silicate nanocomposites. 1 . Preparation, characterization, and mechanical properties. Journal of Nanoscience and Nanotechnology, 2: 171-176.

Sinha Ray, S., Yamada, K., Okamoto, M., Ogami, A., \& Ueda, K. (2003). New polylactide/layered silicate nanocomposites. 3 . High performance biodegradable materials. Chemistry of Materials, 15: 1456-1465.

Sinha Ray, S., Yamada, K., Okamoto, M., \& Ueda, K. (2002). New polylactide/layered silicate nanocomposite: a novel biodegradable material. Nano Letters, 2: 1093-1096.

Siragusa, G. R., \& Dickson, J. S. (1992). Inhibition of Listeria monocytogenes on beef tissue by application of organic acids immobilized in a calcium alginate gel. Journal of Food Science, 57: 293-298.

Smith, J. P., Hoshino, J., \& Abe, Y. (1995). Interactive packaging involving sachet technology. In M. L. Rooney (Ed.), Active foodpackaging (pp. 143-173). Glasgow: Blackie Academic and Professional.

Smits, A. L. M., Ruhnau, F. C., \& Vliegenthart, J. F. G. (1998). Ageing of starch based systems as observed by FT-IR and solid state NMR spectroscopy. Starch, 50 (11-12): 478- 483 .

Steinbuchel, A. (2003). General aspects and special applications. In Biopolymers, 10. Weinheim, Germany: Wiley-VCH Verlag $\mathrm{GmbH}$.

Stewart, C. M., Tompkin, R. B., \& Cole, M. B. (2002). Food safety: new concepts for the new millennium. Innovative Food Science \& Emerging Technologies, 3, 105-112.

Tharanathan, R. N. (2003). Biodegradable films and composite coatings: past, present and future. Trends in Food Science \& Technology, 14 (3): 71-78.
Tortora, M., Vittoria, V., Galli, G., Ritrovati, S., \& Chiellini, E. (2002). Transport properties of modified montmorillonite-poly(3caprolactone) nanocomposites. Macromolecular Materials and Engineering, 287 (4): 243-249.

Trznadel, M. (1995). Biodegradable polymer materials. International Polymer Science and Technology, 22 (12): 58-65.

Vermeiren, L., Devlieghere, F., Van Beest, M., de Kruijf, N., \& Debevere, J. (1999). Developments in the active packaging of foods. Trends in Food Science \& Technology, 10: 77-86.

Wei, M., Shi, S., Wang, J., Li, Y., \& Duan, X. (2004). Studies on the intercalation of naproxen into layered double hydroxide and its thermal decomposition by in situ FT-IR and in situ HT-XRD. Journal of Solid State Chemistry, 177: 2534-254.

Whistler, R. L., \& Daniel, J. R. (1990). Functions of polysaccharides in foods. Food additives. New York, NY: Marcel Dekker, Inc. (pp. 395-424).

Wilhelm, H. M., Sierakowski, M. R., Souza, G. P., \& Wypych, F. (2003). Starch film reinforced with mineral clay. Carbohydrate Polymers, 52: 101-110.

Wilson Jr., O. C., Olorunyolemi, T., Jaworski, A., Borum, L., Young, D., Siriwat. (1999). Surface and interfacial properties of polymer-intercalated layered double ydroxide nanocomposites. Applied Clay Science, 15: 265-279.

Wurzburg, O. B. (1986). Modified starches: Properties and uses. Boca Raton, FL: CRC Press.

Yan, S. S., \& Gilbert, J. M. (2004). Antimicrobial drug delivery in food animals and microbial food safety concerns: an overview of in vitro and in vivo factors potentially affecting the animal gut microflora. Advanced Drug Delivery Reviews, 56: 1497-1521.

Yoon, S. Y., \& Deng, Y. (2006). Clayestarch composites and their application in papermaking. Journal of Applied Polymer Science, 100 (2): 1032-1038.

Zheng, J. P., Li, P., Ma, Y. L., \& Yao, K. D. (2002). Gelatine/ montmorillonite hybrid nanocomposite. I. Preparation and properties. Journal of Applied Polymer Science, 86: 1189-1194. 